\title{
Pearls \& Oy-sters: A rare presentation of Whipple disease
}

\section{Still waters run deep}

Anne T. Kloek, MD, Jurgen R. Piet, MD, PhD, and Kirsten S. Adriani, MD, PhD

Neurology ${ }^{\circledR}$ 2020;94:e758-e761. doi:10.1212/WNL.0000000000008976
Correspondence

Dr. Kloek

a.t.kloek@amsterdamumc.nl

\section{Pearls}

- Neurologic manifestations occur in $20 \%-40 \%$ of patients with Whipple disease, a rare infectious disorder caused by the bacterium Tropheryma whipplei.

- Neuro-Whipple should be considered in patients with diverse unexplained neurologic and psychiatric symptoms with concurrent arthritis and gastrointestinal symptoms.

- The most common - though nonspecific-symptoms in neuro-Whipple are cognitive dysfunction (dementia or memory impairment) and psychiatric signs, such as personality changes and depression.

\section{Oy-sters}

- A diagnostic delay occurs often, due to the nonspecific symptoms and the rarity of Whipple disease. However, timely diagnosis and treatment will improve prognosis, stressing the importance of early recognition.

- Periodic acid-Schiff (PAS) staining, PCR, or immunohistochemistry on biopsy specimens of the involved organs can be negative despite presence of Whipple disease. In any suspected patient, a combination of all these diagnostics should be considered in the diagnostic workup.

\section{Case report}

A 70-year-old man was referred to the neurology outpatient clinic with an abnormal MRI scan of the brain, which was performed by the ear, nose, and throat specialist because of complaints of subacute tinnitus. MRI brain showed hyperintensities in the parahippocampal gyrus on both sides (figure 1). His medical history consisted of a radical removal of a thymoma, TIAs, atrial fibrillation on anticoagulative therapy, hypertension, benign prostatic hyperplasia, and coxarthrosis.

Except for tinnitus, the patient reported no neurologic complaints, and neurologic examination was unremarkable. However, a few weeks later, his partner reported that the patient had sleeping disturbances, with reversal of his day-night cycle, and fluctuating disorientation manifesting as getting lost in his own house. On other days, he behaved normally. Gradually he became more passive, sitting on the couch most of the day. He had memory problems like forgetting the latest news items.

The patient was admitted to the neurology ward. Our differential diagnosis was limbic encephalitis due to an autoimmune or infectious cause, systemic disease such as sarcoidosis, or CNS localization of a malignancy. Due to progression of symptoms, MRI scan of the brain was repeated, showing no progression or new abnormalities. Laboratory investigation-aiming to

From the Department of Neurology (A.T.K.), Amsterdam Neuroscience, Amsterdam UMC, University of Amsterdam; Department of Neurology (J.R.P., K.S.A.), OLVG Hospital, Amsterdam; Department of Neurology (J.R.P., K.S.A.), Zaans Medisch Centrum, Zaandam; and Department of Viroscience (K.S.A.), Erasmus MC, Rotterdam, the Netherlands.

Go to Neurology.org/N for full disclosures. Funding information and disclosures deemed relevant by the authors, if any, are provided at the end of the article. 

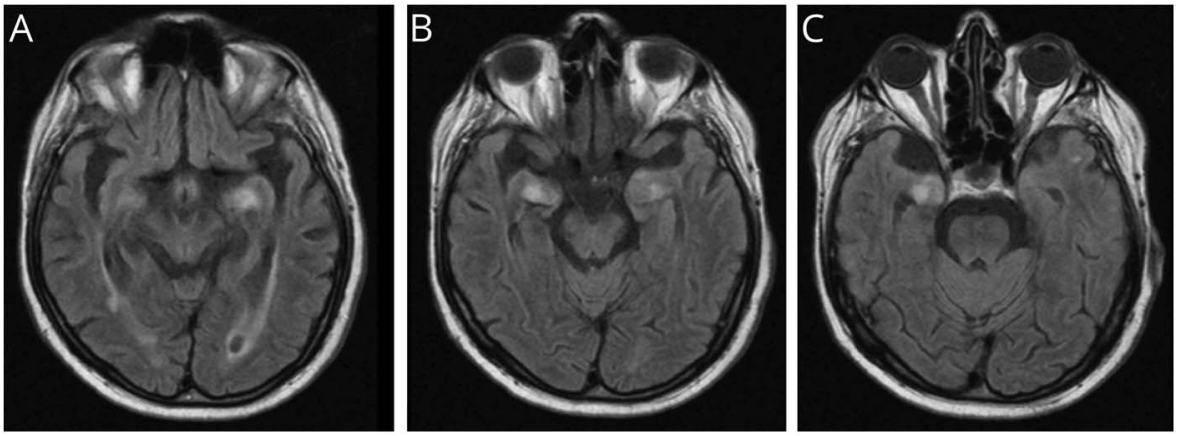

(A-C) Axial T2 fluid-attenuated inversion recovery without gadolinium shows bilateral hyperintensities in the parahippocampal gyrus, more pronounced on the right side.

investigate infectious, malignant, and systemic diseasesshowed slightly increased C-reactive protein and erythrocyte sedimentation rate but no other abnormalities. Serum antineuronal antibodies ( $\mathrm{Hu}, \mathrm{Yo}, \mathrm{Ri}$, Tr, amphiphysin, CV2, Ma1, Ma2, AMPA-R, and VGKC-R) were negative. EEG showed no signs of encephalitis or epilepsy. A lumbar puncture was performed and showed a pleiocytosis of 17 cells/ $\mu \mathrm{L}(85 \%$ mononuclear) and a normal protein and glucose level. Antineuronal antibodies ( $\mathrm{Hu}, \mathrm{Yo}, \mathrm{Ri}$, Tr, amphiphysin, CV2, Ma1, Ma2, Caspr2) in CSF were negative. Borrelia, Lues, and Coxiella burnetii diagnostics in blood and CSF were negative as well. A CT scan of the thorax and abdomen was performed with the aim of investigating the presence of malignancy associated with paraneoplastic encephalitis and there were no signs of recurrence of the thymoma. FDG PET CT showed no pathologic uptake elsewhere besides the brain. After all the investigations had negative results, the patient withdrew himself from further testing and admission in the hospital.

Over a few months, the clinical situation of the patient gradually deteriorated, and he returned to the hospital. $\mathrm{He}$ slept during most of the day, he was incontinent for urine, his memory problems worsened, and his defecation pattern had changed into watery diarrhea. On neurologic examination, the patient had a fluctuating consciousness, was bradyphrenic, was disorientated in time and place, and had visual hallucinations. He had an expressive aphasia and was not able to speak fluently. He had double-sided ptosis and pathologic plantar reflexes. His walking pattern was unstable. The clinical diagnosis was limbic encephalitis, either autoimmune mediated or based on an infectious cause. Repeated lumbar puncture showed a pleiocytosis of 33 cells/ $\mu \mathrm{L}$ and no other abnormalities. Immunophenotyping showed no abnormalities. Repeated antineuronal antibodies testing and PCRs on viruses were all negative.

Because the patient was deteriorating and a diagnosis was lacking, a brain biopsy was performed. No corticosteroids were started pending the results of the brain biopsy. On pathologic examination, periodic acid-Schiff (PAS) staining was positive, showing macrophage infiltration containing bacilli, fitting Whipple disease (figure 2). The diagnosis was confirmed with a PCR showing Tropheryma whipplei DNA in the brain tissue.

\section{Discussion}

Whipple disease is a multisystemic infectious disorder caused by the bacterium $T$ whipplei. The disease was first described by Dr. George Hoyt Whipple ${ }^{1}$ in 1907 as "intestinal lipodystrophy." He described a case of a 36-year-old patient with
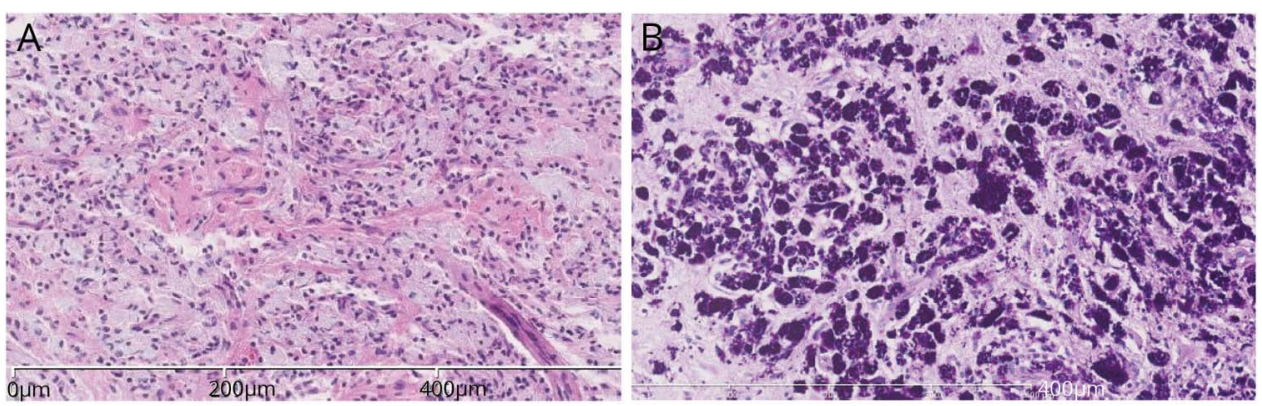

(A) Hematoxylin \& eosin staining shows macrophage infiltration. (B) Periodic acid-Schiff staining shows macrophages containing bacilli. 
malabsorption, mesenteric lymphadenopathy, arthritis, and skin pigmentation. ${ }^{1}$ The etiology of this disease was unknown until the bacteria were demonstrated with electron microscopy in $1961 .^{2}$

The incidence of Whipple disease is very low, approximately less than 1 per 1,000,000 population. ${ }^{2}$ Most patients are men $(\sim 85 \%)$ of Caucasian origin with a mean age at diagnosis of 55 years. ${ }^{2,3}$ The ecologic niche of the bacterium is not certain but $T$ whipplei DNA is more often found in waste water originating from rural communities and prevalence of the disease is higher among sewer workers. ${ }^{4}$ It is assumed that transmission takes place via the fecal-oral route or via drinking contaminated water. ${ }^{4,5}$

The discrepancy between the rarity of disease with the widespread presence of $T$ whipplei in the environment and the frequency of healthy carriers contribute to the idea that host factors play a role in the pathogenesis of Whipple disease., ${ }^{2,4}$ Possibly there is a genetic predisposition, supported by a higher incidence in white men and a higher frequency of the HLA-DRB1 ${ }^{*} 13$ and HLA-DQB1 ${ }^{*} 06$ alleles among those with the disease. ${ }^{4,6}$ However, because only a minority of people with these human leukocyte antigen haplotypes are infected, additional factors must be involved in the pathogenesis of Whipple disease. ${ }^{6}$

The classical presentation of Whipple disease is arthralgia, weight loss, diarrhea, and abdominal pain. ${ }^{3}$ The joint and gastrointestinal symptoms can progress after months or even years to an abdominal wasting syndrome and lymphadenopathy. ${ }^{3}$ These advanced stages of gastrointestinal manifestations are frequently accompanied by CNS involvement, but isolated CNS infection without intestinal tract involvement can occur as well. ${ }^{7,8}$ Neurologic manifestations occur in $20 \%-40 \%$ of all patients. ${ }^{3,8}$ The most common symptoms reported are related to meningoencephalitis: cognitive dysfunction such as dementia (28\%) or memory impairments (25\%) and psychiatric signs (19\%) such as personality changes and depression. ${ }^{7,8}$ Other frequently described neurologic signs are disturbances in ocular movement like supranuclear ophthalmoplegia (32\%-59\%)., ${ }^{8,9}$ Oculomasticatory myorhythmia or oculofacioskeletal myorhythmia, a slow smooth convergent-divergent pendular nystagmus associated with synchronous contractions of other body parts, occur less frequently ( $8 \%-24 \%)$ but are considered pathognomonic for Whipple disease. ${ }^{8,9}$ Dysfunction of the hypothalamus occurs in 11\%-19\% of patients and can manifest as sleep disorders (41\%) like insomnia or hyperinsomnia., Infection of different brain regions can lead to several neurologic signs: cerebellar ataxia (11\%-39\%), pyramidal symptoms $(10 \%-44 \%)$, myoclonic signs $(15 \%-19 \%)$, seizures $(11 \%-17 \%)$, headache $(28 \%)$, or signs of myelopathy $(11 \%) .^{7-9}$

Diagnosis of neuro-Whipple can be difficult due to the broad spectrum of nonspecific clinical features and its rarity. ${ }^{10}$ The reported range between first symptoms and diagnosis is $0-30$ years, with an average of 6.4 years. ${ }^{3}$ If clinically suspected, an upper gastrointestinal endoscopy of the small intestine should be performed, which can show macroscopic villous atrophy and lipodystrophy. ${ }^{5,10}$ In biopsy specimens of involved tissues (e.g., duodenum, synovia, brain) or CSF, PAS staining, $T$ whipplei PCR, and immunohistochemistry should be performed. ${ }^{5}$ Histology might reveal tissue infiltration with foamy macrophages containing PAS-positive rod-shaped structures ( $T$ whipplei) in their cytoplasm. ${ }^{5} T$ whipplei can be detected by PCR targeting specific gene parts of the bacterium or by immunohistochemical staining with $T$ whipplei antibodies. ${ }^{5}$ Final diagnosis requires 2 out of 3 positive results of these specific diagnostic tests on biopsy or CSF specimens. ${ }^{5}$ MRI scan is recommended in the evaluation of suspected neuro-Whipple, although findings can range from a normal scan to focal $\mathrm{T} 2$ hyperintensities or diffuse cerebral atrophy. ${ }^{7}$

The optimal choice and duration of antibiotic treatment of Whipple disease is unclear, since only small randomized controlled trials have been performed. ${ }^{11}$ Current treatment strategy is an initial 2-week IV antibiotic treatment regimen followed by long-term (>12 months) oral maintenance therapy. ${ }^{5} \mathrm{IV}$ antibiotics of choice are ceftriaxone, penicillin, or meropenem, and for maintenance, doxycycline or cotrimoxazole. ${ }^{5,11}$ Untreated neuro-Whipple is always fatal. ${ }^{8}$ Patients with Whipple disease initially treated with immunosuppressive therapy with CNS manifestations or a relapse of disease after an initial good response on treatment have a poorer prognosis. ${ }^{8}$ Neurologic defects often result from irreversible tissue damage and therefore may not reverse by prolonged antibiotic treatment. ${ }^{5,8}$ Possibly nowadays prognosis is improving, with mortality rates of neuro-Whipple reported of $11 \%$, due to earlier diagnosis and better use of antimicrobial therapy. ${ }^{7}$ Metagenomic sequencing of CSF might also improve timely diagnosis in the future. Timely diagnosis of neuro-Whipple is essential and therefore this disease should be considered in unexplained systemic illness with CNS involvement.

\section{Follow-up of the case}

There was a delay of 15 months between the first MRI and diagnosis, despite extensive investigations and testing. Treatment with IV ceftriaxone was started immediately after diagnosis. After finishing 2 weeks of IV therapy, antibiotics were switched to oral cotrimoxazole. At that time, the patient's clinical condition was poor; he was bedridden, only awake after verbal stimuli, but did not respond adequately to questions or simple commands. He was discharged to a nursing home and after 2 months transferred to a rehabilitation center, where he stayed for several months before returning home. During this time, his clinical condition was improving slowly. At the time of writing this case report, he could walk with assistance of a walking aid and was able to 
have simple conversations, but still needed help for most daily activities.

Speculating about the source of infection, the patient's partner reported that the patient lived in a house containing an old draw-well, from which he frequently drank water. The patient had multiple episodes of diarrhea and joint pains over recent years. The water quality of the draw-well was investigated and appeared to be heavily polluted by a nearby cemetery, possibly explaining the route of infection.

\section{Author contributions}

A.T. Kloek: drafting/revising the manuscript, data acquisition, accepts responsibility for conduct of research and final approval. J.R. Piet: drafting/revising the manuscript, accepts responsibility for conduct of research and final approval. K.S. Adriani: drafting/revising the manuscript, data acquisition, analysis or interpretation of data, accepts responsibility for conduct of research and final approval, acquisition of data.

\section{Study funding}

No targeted funding reported.

\section{Disclosure}

The authors report no disclosures relevant to the manuscript. Go to Neurology.org/N for full disclosures.

\section{References}

1. Whipple GH. A hitherto undescribed disease characterized anatomically by deposits of fats and fatty acids in the intestinal mesenteric lymphatic tissues. Bull Johns Hopkins Hosp 1907;18:382-391.

2. El-Abassi R, Soliman MY, Williams F, England JD. Whipple's disease. J Neurol Sci 2017;377:197-206.

3. Lagier JC, Lepidi H, Raoult D, Fenollar F. Systemic Tropheryma whipplei: clinical presentation of 142 patients with infections diagnosed or confirmed in a reference center. Medicine 2010;89:337-345.

4. Schoniger-Hekele M, Petermann D, Weber B, Muller C. Tropheryma whipplei in the environment: survey of sewage plant influxes and sewage plant workers. Appl Environ Microbiol 2007;73:2033-2035.

5. Schneider T, Moos V, Loddenkemper C, Marth T, Fenollar F, Raoult D. Whipple's disease: new aspects of pathogenesis and treatment. Lancet Infect Dis 2008 ;8: 179-190.

6. Martinetti M, Biagi F, Badulli $\mathrm{C}$, et al. The HLA alleles DRB1* 13 and DQB1*06 are associated to Whipple's disease. Gastroenterology 2009;136:2289-2294.

7. Compain C, Sacre K, Puechal X, et al. Central nervous system involvement in Whipple disease: clinical study of 18 patients and long-term follow-up. Medicine 2013;92:324-330.

8. Gerard A, Sarrot-Reynauld F, Liozon E, et al. Neurologic presentation of Whipple disease: report of 12 cases and review of the literature. Medicine 2002;81:443-457.

9. Bally JF, Meneret A, Roze E, Anderson M, Grabli D, Lang AE. Systematic review of movement disorders and oculomotor abnormalities in Whipple's disease. Mov Disord 2018;33:1700-1711

10. Louis ED, Lynch T, Kaufmann P, Fahn S, Odel J. Diagnostic guidelines in central nervous system Whipple's disease. Ann Neurol 1996;40:561-568.

11. Feurle GE, Junga NS, Marth T. Efficacy of ceftriaxone or meropenem as initial therapies in Whipple's disease. Gastroenterology 2010;138:478-486. 


\section{Neurology}

Pearls \& Oy-sters: A rare presentation of Whipple disease: Still waters run deep

Anne T. Kloek, Jurgen R. Piet and Kirsten S. Adriani

Neurology 2020;94;e758-e761 Published Online before print February 3, 2020

DOI 10.1212/WNL.0000000000008976

This information is current as of February 3, 2020

\section{Updated Information \&} Services

References

Subspecialty Collections

Permissions \& Licensing

Reprints including high resolution figures, can be found at: http://n.neurology.org/content/94/7/e758.full

This article cites 11 articles, 1 of which you can access for free at: http://n.neurology.org/content/94/7/e758.full\#ref-list-1

This article, along with others on similar topics, appears in the following collection(s):

Bacterial infections

http://n.neurology.org/cgi/collection/bacterial_infections Encephalitis

http://n.neurology.org/cgi/collection/encephalitis

Information about reproducing this article in parts (figures,tables) or in its entirety can be found online at:

http://www.neurology.org/about/about_the_journal\#permissions

Information about ordering reprints can be found online:

http://n.neurology.org/subscribers/advertise

Neurology ${ }^{\circledR}$ is the official journal of the American Academy of Neurology. Published continuously since 1951 , it is now a weekly with 48 issues per year. Copyright (C) 2020 American Academy of Neurology. All rights reserved. Print ISSN: 0028-3878. Online ISSN: 1526-632X.

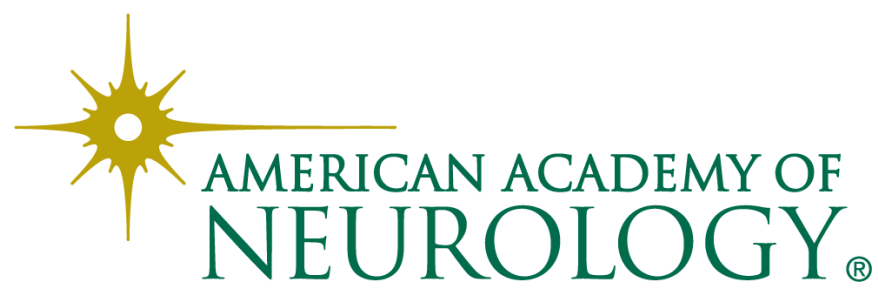

